\title{
تأثير موقف اللغة لطلاب معهد الشيخ حسن اليماني على قدرة التحدث باللغة العربية
}

\author{
Abu Dzar al-Qifari ${ }^{1}$ \\ Universitas Islam Negerai Alauddin Makassar ${ }^{1}$ \\ Email:abusokganteng@gmail.com \\ DOI: https://doi.org/10.24252/saa.v6i2.7126
}

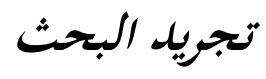

قدم الباحث في هذه الرسالة تأثير موقف اللغة لطلاب معهد الشيخ حسن اليمانى علي قدرة التحدث باللغة العربية العام 2018. وأهداف هذا البحث هي لمعرفة موقف اللغة لطلاب معهد الشيخ حسن اليمانى، ولمعرفة قدرة الطلاب على التحدث باللغة العربية في معهد الشيخ حسن اليماني، ولمعرفة تأثير موقف اللغة لطلاب معهد الشيخ حسن اليماني على قدرة التحدث باللغة العربية.

نوع هذا البحث هو بحث ميدني كمي، البمموع الكلى في هذ البحث جميع طلاب معهد الشيخ حسن اليمانى العام 2018. وأما الطريقة المستعملة في أخذ العينة النموذجية هي الملاحظة، والإستطلاع والوثيقة. ولذلك في هذا البحث، قام الباحث بأخذ العينات من الطلاب معهد الشيخ حسن اليمانى بلغ بحموعها 40 طالبا، وطريقة تحليل البيانات هي تحليل الإحصاء الوصْفي وتحليل الاستدلالي.

$$
\text { نتائج موقف اللغة لطلاب معهد الشيخ حسن اليمانى في المسافة 40-43 بتردد من } 10 \text { ونسبة }
$$

25\% دخلت في فئة منخفضة. وفي المسافة 44-47 بتردد من 30 ونسبة \% 75 دخلت في فئة مرتفع. وأما نتائج قدرة الطلاب علي التحدث باللغة العربية في المسافة 73-78 بتردد من 4 ونسبة 10\% دخلت في فئة منخفضة جدا. وفي المسافة 79-84 بتردد من 20 ونسبة 50\% دخلت في فئة منخفضة. وفي المسافة 85-90 بتردد من 11 ونسبة \% 5، 27 دخلت من فئة كافا. وفي المسافة 91-96 بتردد من 5 ونسبة \% \% 5، 12 دخلت في فئة كافا جدا. وفي إختبار الأحصاء الإستدلالي فيعرف أكبر من hitung مردود و مقد Ho مقبول. فالإستنتاج أن موقف اللغة لطلاب معهد الشيخ حسن اليمانى لها تأثير إجابي على 
قدرقم في التحدث باللغة العربية في مستوى جيد جدا. لذلك يحتاج الطلاب إلى إتخاذ موقف إيجابي والقيام بوظائفهم بحيث تنمو الإرادة في التطوير والحفاظ على اللغة العربية.

باللغة العربية العام الرئيسة: تأثير موقف اللغة لطلاب معهد الشيخ حسن اليماني على قدرة التحلث 2018

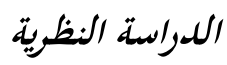

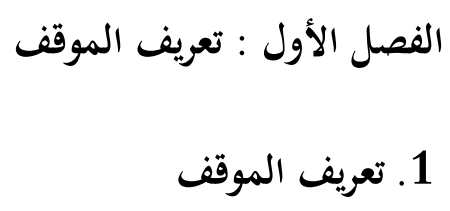

المواقف قد يشير إلى شكل الجسم، وتستقيم، والسلوك أو الإيماءات، والإجراءات أو الإجراءات

المتخذة على أساس العرض (الإنشاء، والمعتقدات، أو الآراء) كرد فعل لشيء أو حدث. في الواقع ، هذا الموقف هو ظاهرة نفسية تظهر عادة في شكل عمل أو سلوك. 1 في معجم الوسيط الموقف هو الموضع يقف فيه الإنسان

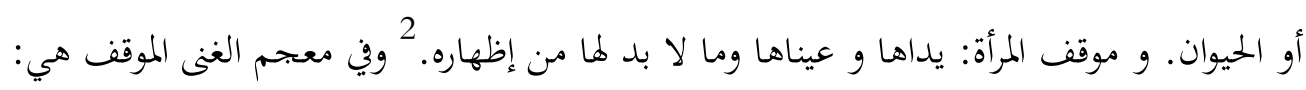

أ. عبر عن موقفه بشجاعة: استعداد نفسي أو رأي إزاء شخص أو قضية ما يعبر فيه صاحبه عما يشعر

به- موقف حرج : موقف عدائي : إستطاع أن يسيطر على الموقف كليا وبصرامة وحزم. غسان كنفاني :

$$
\text { ب. ب. المخاذ الحزب مواقف موقف عمَلِ لا موقف كلام. }
$$

1 عبد الخير ويوني آجوستينا. Sosiolinguistik Perkenalan Awal. (جاكرتا: 2010,PT. Refika Cipta). ص. 149

$$
\begin{aligned}
& \text { 2 شوقى ضيف، المعتم الوسيط . (مصرى: مكتبة صورق الدولية، 2011) 2013.ص. }
\end{aligned}
$$

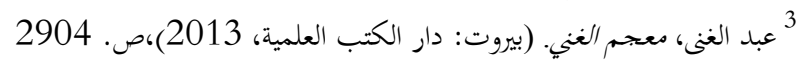


أن المواقف لا تتشكل بطبيعتها الفطرية، ولكنها تتشكل من خلال التعلم. وتماشيا مع هذا، طرح أربع حجج تطوير المواقف، وهي(1) تطور الموقف في عملية الرغبة الرضا،(2) يتم تشكيل موقف الفرد من خلال المعلومات التي يتعرض لها، (3) بحموعة من الانتماء للفرد مساعدة في تحديد تشكيل مواقفه، (4) المواقف

4 بالعنف الفرد تعكس شخصيته.

يوضح الافتراض الأول أن المواقف تطور من أجل تلبية الرغبة أو الحاجة. الشخص الذي يحاول إشباع رغباته سيطور موقفًا وفقًا لتلك الرغبة. سيطور مواقف إيجابية بتحاه الأشياء التي يمكن أن ترضي أو تساعد الجهود المبذولة لتلبية احتياجاته أو احتياجاته. بدلاً من ذلك، سيطور موقفًا سلبيًا تجاه الشيء الذي يعوق الجهد في تلبية احتياجاته أو إرادته.

قدرة التحدث باللغة العربية

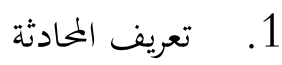

في اللغة، المحادثة يأتي من اللغة العربية التي نشأت منها فعل الماضى المجرد له معنى هو المحادثة أو الحوار أو التحدث. 5 في حين يأتي المحادثة من فعل ثلاثى المزيد يجتوي على المعنى المتبادل. ثم يحتوي المحادثة معنى الحديث أو التحدث مع بعضنا البعض. أن تدريس اللغة فيه يحتوي عناصر مثل نظام الصوت، والمهارات اللغوية التي تتكون من القراءة، والكتابة، والتحدث، والاستماع. ولتدريب وتعليم كل من هذه العناصر والمهارات، تم تطوير

أساليب أو تقنيات مختلفة.

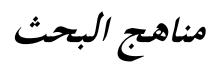

الفصل الأول : نوع و مكان البحث

4 فنح الرمان. Sosiolinguistik Suatu Pendekatan Pembelajaran Bahasa dalam Masyarakat Multikultural (جنجاكرتا: Graha Ilmu،

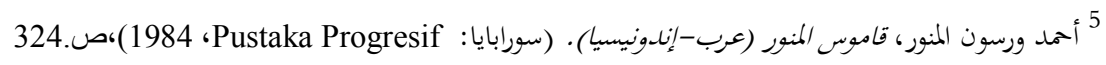

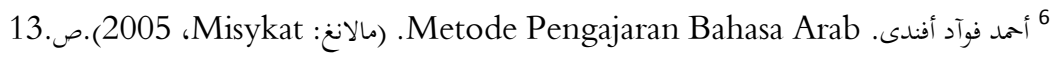


البحث المستخدم في هذه الدراسة هو نوعي وصفي كمي. تصميم وصفي نوعي يهدف إلى وصف وتحليل الظواهر والأحداث والأنشطة الإجتماعية والمواقف والمعتقدات والتصورات، والأفكار من شخص بشكل فردي أو في مجموعات. ${ }^{7}$ قدف الدراسة الوصفية إلى توفير بيانات شاملة قدر الإمكان عن البشر والظروف والأعراض الأخرى ووصف الظروف في الحالة. 8

وإختار الباحث إلى إستخدام المنهج الوصفي النوعي لأن الباحث سيصف كما تأثير موقف اللغة لطلاب معهد الشيخ حسن اليمانى على قدرة التحدث باللغة العربية العام 2018.

موقع تحديد البحث مهم للغاية من أجل حساب البيانات التي تم الحصول عليها. أما بالنسبة لهذا البحث، فإن الكاتب يأخذ موقع البحث في معهد الشيخ حسن اليمان جمبلاغيان. أخذ الباحث موقع البحث على تلك المدرسة لأن الطلاب يستخدمون اللغة العربية كلغة حياقم اليومية. الفصل الثانى : المجموع الكلى وقال الدوكتورنديس حرمان وريستو في كتابة Pengantar Metodologi Penelitian " موصول مناهج البحث" بتعريف تفصيل عن المجموع الكلي: " البمموع الكلي هو جميع موضوعات البحث التي تتكون من إنسان وحيوان ونبات وظاهرة درجة إختبار أو حادثة كمصدر معلومات لها شخصيات أو خصائص فن البحث". 9 من البيان المذكور فعرف الباحث أنّ البمموع الكلى هو جميع طلاب معهد الشيخ حسن اليمانف الذين يشتركون في تدريب اللغة العربية 207 طالبا. الفصل الثالث : العينة النموذجية

23 ننا سكماديناتا شوضح. Metode Penelitian Pendidikan.(باندونغ: 2015.PT. Remaja Rosdakarya)، ص.60. 24 عريف فورقان,Pengantar Penelitian Dalam Pendidikan

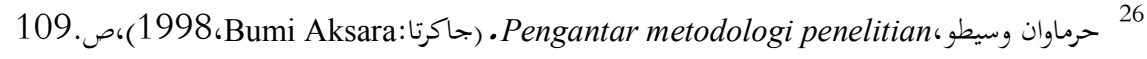


قبل أن يشرح الباحث العينة النموذجية في هذا البحث ينبغي له أن يشرح أولا تعريف العينة النموذجية في هذا البحث العلمية العينة عند سوحرسيمي أريكونتوا هي:" جزء أو نائب المجموع الكلي المراد بحثه". 10 قال سوغيونو أن العينة هي:" العينة هي جزء من أجزاء البمموع الكلي الذي تمتاز هما". 11 وقال أيضا : " اذا كان مصدر المواد أقل من 100 شخص فيحسن للباحث أن يتناول كلهم، كان البحث بحث العدد/البحموع الكلى.فاذاكان اكثرمن 100 شخص فأخذ الباحث أن يختار منهم العينة النموذجية تتراوح بين20-30.12 أما عدد طلاب معهد الشيخ حسن يمانى الذين يشتركون فن تدريب اللغة العربية 207 شخص فيتناول الباحث يأخذ 40 طالبا.

\section{الفصل الرابع : طريقة جمع البيانات}

سيحصل البحث على بيانات تمثيلية في حالة استخدام طريقة قادرة على كشف البيانات المطلوبة .لذلك، في جمع البيانات يستخدم الباحث بعض الطرق، وهي الإستطلاع، والملاحظة، والوثيقة.

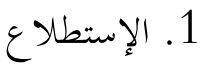

الإستطلاع هو طريقة جمع البينات و يتم ذالك من خلال عرض عدد من الأسائلة المكتوبة للخصول على معلومات من الجميبين. أساس استبيان هو قائمة من الأسئلة أو البيانات التي يجب ملؤها من قبل الشخص لقياس. نوع الاستبيان المستخدم في هذه الدراسة هو استبيان مع أسئلة مغلقة. أي أن الباح قد قدموا إجابات بديلة للبيانات الموجودة، في شكل موافق تام (SS)، موافق (SS)، غير موافق (TS)، وغير موافق تام (STS) . الفصل الخامس : إجراءات البحث

ويتم جمع البينات البحثية لإستخدام الصكوك المذكورة آنفا،و هي ملء الإستبينات و الوثائق، مصنوعة مباشرة.

27 سوحرسيمي أريكونتوا.Prosedur Penelitian

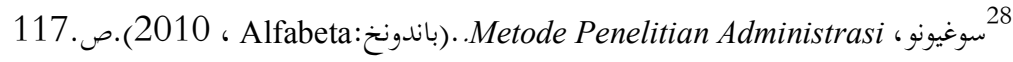

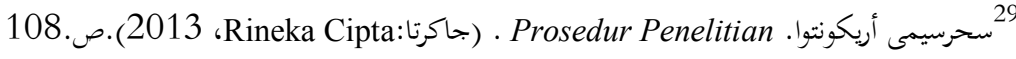




$$
\begin{aligned}
& \text { 1 } \\
& \text { جعل أدوات البحث لا ستخدامها في جمع البينات } \\
& \text { 2. مرحلة التنفيذ } \\
& \text { تقديم إختبار الطلبة } \\
& \text { 3 }
\end{aligned}
$$

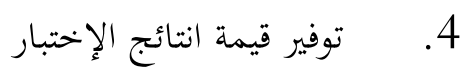

$$
\begin{aligned}
& \text { الفصل السادس: طريقة تحليل المواد } \\
& \text { يستخدام الباحث إثنتا طريقتين في تحليل البينات هما الإحصاء الوصف و الإحصاء الإستجدلالي. }
\end{aligned}
$$

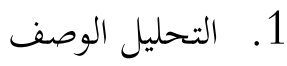

$$
\begin{aligned}
& \text { إستخدام الإحصاء الوصف لإجحابة المشاكلة الأولى والثانية باستخدام يكون كالتالى: }
\end{aligned}
$$

1. Tabulasi frekuensi, dengan langkah-langkah sebagai berikut:

a. Rentang (RT) adalah nilai terbesar (NT) dikurang nilai terkecil (NR)

$R T=N T-N R^{13}$

Keterangan:

$\mathrm{RT}=$ Rentang

NT $=$ Nilai Tertinggi

$\mathrm{NR}=$ Nilai Rendah

b. Banyak kelas interval

Banyak kelas interval $(\mathrm{I})=1+(3,3) \log n$

Keterangan:

$n=$ Banyaknya data

13 نور السلام. Statistika Penelitian، (مكاسر: طبعة: 1، علاء الدين ينفرستى فريس، 2011)، ص.62 
c. Panjang kelas interval

Panjang kelas $(\mathrm{p})=$ rentang/ banyak kelas

2. Mean rata-rata $\left(x^{-}\right)$

$$
x^{-}={ }^{\Sigma} f 1 x i i^{\Sigma} f 1
$$

Dengan:

$x^{-}$: Mean rata-rata

$x i$ data ke-i sampai ke -n

N: Banyaknya data

F1: frekuensi masing-masing nilai $\mathrm{xi}^{14}$

3. Presentase (\%)

$$
\mathrm{P}=\mathrm{fI} n \times 100 \%
$$

\section{Keterangan:}

$\mathrm{P}=$ persentase selisih antara $\mathrm{X}$ dengan $\mathrm{Y}$

$F=$ frekuensi untuk selisih antara $\mathrm{X}$ dengan $\mathrm{Y}$

$\mathrm{N}=$ Jumlah sampel $^{15}$

4. Menghitung simpangan baku (standar deviasi)

$$
\sqrt{\frac{\sum f i(x i-x)^{2}}{n-1}} S_{\mathrm{D}}=
$$

5. Membuat tabel kategorisasi skor

$$
\text { Interval }=\frac{\text { rentang nilai }}{\text { banyak kelas }}
$$

34

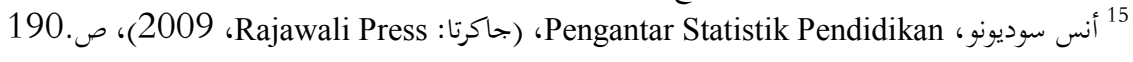




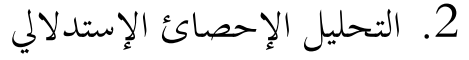

$$
\begin{aligned}
& \text { تستخدم الإحصاء الإستدلالي لإختبار فرضية البحث و لمعرفة وجود أن عدم علاقة بين مفاهم الطلاب } \\
& \text { عن اللغة العربية و نتائج تعلمهم في المدرسة العالية المهنية المحمدية مكاسر. لأغراض إستخدام تحليل } \\
& \text { علاقة الإنتاج حظة(rxy) } \\
& r_{x y}=\frac{\sum x y}{\sqrt{\left\{\Sigma X^{2}\right\}\left\{\sum Y^{2}\right\}}} \text { Rumusnya : }
\end{aligned}
$$

\section{Keterangan:}

rxy $=$ koefisien korelasi variabel $x$ dengan variabel $y$

$\mathrm{xy}=$ jumlah hasil perkalian antara variabel $\mathrm{x}$ dengan variabel $\mathrm{y}$

$\mathrm{x}=$ jumlah hasil setiap item

$\mathrm{N}=$ jumlah subyek penelitian

Nilai dari koefisien korelasi (r) terletak antara -1 dan $+1(-1 \leq \mathrm{r} \leq+1)$

a. Jika $r=+1$, terjadi korelasi positif sempurna antara variabel $\mathrm{x}$ dan $\mathrm{y}$

b. Jika $r=-1$, terjadi korelasi negatif sempurna antara variabel $\mathrm{x}$ dan $\mathrm{y}$

c. Jika $r=0$, tidak terdapat korelasi antara variabel $\mathrm{x}$ dan $\mathrm{y}$

d. Jika $0<\mathrm{r}<+1$, terjadi korelasi positif antara variabel $\mathrm{x}$ dan $\mathrm{y}$

e. Jika $-1<\mathrm{r}<0$, , terjadi korelasi negatif antara variabel $\mathrm{x}$ dan $\mathrm{y}$

H0 : rxy $=0$ 
Ha : rxy tidak $=0$

Kaidah keputusan:

a) Jika nilai a 0,05 lebih kecil atau sama dengan nilai probabilitas sig atau $[0,05 \leq$ sig $]$, maka H0 diterima dan Ha ditolak, artinya tidak ada korelasi

b) Jika nilai a 0,05 lebih besar atau sama dengan nilai probabilitas sig atau $[0,05 \geq \operatorname{sig}]$, maka $\mathrm{H} 0$ ditolak dan Ha diterima, artinya ada korelasi

\section{نتائتج البحث والمناقشة}

الفصل الأول : تاريخ إنشاء المعهد 1. ت تاريخ إنشاء المعهد

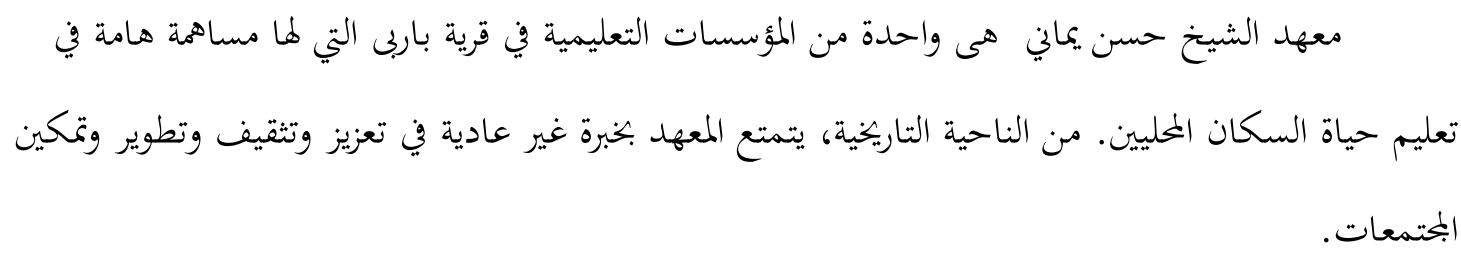

في السنة 1926، جاء هناك شيخ من المملكة العربية السعودية ودعا الشيخ سعيد اليماني إلى منطقة

جمبلاغيان بوليوالى مندار سولاويسي الغربية وعائلنه المكونة من الشيخ حسن اليماني والشيخ عمر اليماني. وهم يعيشون في منزله حبيب حسن المهالي على وجه التحديد في شارع قرية العلماء من بوندى. ثم تزوج الشيخ حسن اليماني مع شريفة المنورة (الشقيق الأكبر من ك. ح. محمد سعيد المهلي)، والزواج بين الشيخ حسن اليماني و آل شريفة المنورة لديها ابن اسمه طارق اليماني، ولكن الطفل توفي عندما كان تحت والده إلى المملكة العربية السعودية. الشيخ حسن اليماني استقر في جمبلاغيان حوالي 1926-1933 ثم واصل مهمته الإسلامية في ماليزيا. 16 
في عام 1970، عندما ك. ح. محمد سعيد المهدلي قام بالحج) إلتقى الشيخ حسن اليماني. ونصحه كي أنشئت مؤسسة تعليمية إسلامية، لذلك عند وصوله إلى جمبلاغيان نقل هذه الرسالة إلى العلماء في جمبلاغيان، لذلك عقد اجتماع وأخيراً تم التوصل إلى اتفاق لإنشاء مؤسسة تعليمية إسلامية. وفي يوم الجمعة 11 يوليو 1980،ك. ح. محمد سعيد المهلي قرأ المرسوم المتعلق بإنشاء مدرسة شيخ حسن اليماني في مسجد الكبير جمبلاغيان تحت اسم المدرسة معهد الشيخ حسن اليماني. الاسم مأخوذ من اسم الشيخ حسن اليماني كتقدير

\section{الفصل الثانى : موقف اللغة لطلاب معهد الشيخ حسن اليماني}

بالإضافة إلى قدرة الطلاب على التحدث باللغة العربية في معهد الشيخ حسن اليمان، أظهر الطلاب أيضًا موقفًا إيجابيًا بتحاه اللغة العربية.

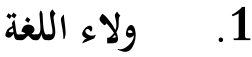

\section{أ. أنا أستخدم اللغة العربية في الفصل (جدوال 4.7)}

يوضح الجدول 4.7 أعلاه آراء الطلاب عن إستخدام اللغة العربية في الفصل الدراسي عند التعلم. لا

يوجد طلاب أو ما يعادل 0\% من يجيبون غير موافق تام عن إستخدام اللغة العربية في الفصل عند التعلم. ثم الطلاب الذين أجابوا غير موافق على أفم يستخدمون اللغة العربية في الفصل 20 طلاب أو ما يعادل 50\%. ثم الطلاب الذين أجابوا موافق على أفم يستخدمون اللغة العربية في الفصل 12 طلاب أو ما يعادل 30\%، والطلاب الذين أجابوا موافق تام على أفم يستخدمون اللغة العربية دائمًا في الفصل 8 طلاب أو ما يعادل $\% 20$

ب. أنا أستخدم اللغة العربية في التكلم مع أصدقائي (جدوال 4.8) يوضح الجدول 4.8 أعلاه آراء الطلاب عن إستخدام اللغة العربية في التكلم مع أصدقائهم. لا يوجد طلاب أو ما يعادل 0\% من يجيبون غير موافق تام عن إستخدام اللغة العربية في التكلم مع أصدقائهم. ثم 17 فخرى تاج الدين، رئيس معهد الشيخ حسن اليماني، مقابلة مع الباحث في المعهد، 23 أكتوبر 2018. 
الطلاب الذين أجابوا غير موافق على أفم يستخدمون اللغة العربية في التكلم مع أصدقائهم 15 طلابا أو ما يعادل 37.5\%. ثم الطلاب الذين أجابوا موافق على أغم يستخدمون اللغة العربية في التكلم مع أصدقائهم 15 طلاب أو ما يعادل 37.5\%، والطلاب الذين أجابوا موافق تام على أفم يستخدمون اللغة العربية في التكلم مع أصدقائهم 10 طلاب أو ما يعادل 25\%.

ج. أنا مسرور باستخدام اللغة العربية مع الأستاذ في الفصل إم خارج الفصل (جدوال 4.9)

يوضح الجدول 4.9 أعلاه آراء الطلاب عن مسرورهم باستخدام اللغة العبية مع الأستاذ في الفصل أم خارج الفصل. لا يوجد طلاب أو ما يعادل 0\% من يجيبون غير موافق تام عن مسرورهم باستخدام اللغة العربية مع الأستاذ في الفصل أم خارج الفصل. ثم الطلاب الذين أجابوا غير موافقة على أغم مسرور باستخدام اللغة العربية مع الأستاذ في الفصل أم خارج الفصل 15 طلاب أو ما يعادل 37.5\%. ثم الطلاب الذين أجابوا موافقة على أفم مسرور باستخدام اللغة العربية مع الأستاذ في الفصل أم خارج الفصل 11 طلاب أو ما يعادل 24.5\%، والطلاب الذين أجابوا بشدة موافقة على أفم مسرور باستخدام اللغة العربية مع الأستاذ في الفصل أم خارج الفصل 14 طلاب أو ما يعادل 35\%.

د. أنا مسرور باستخدام اللغة العربية في الأنشطة الأصفية (جدوال 4.10)

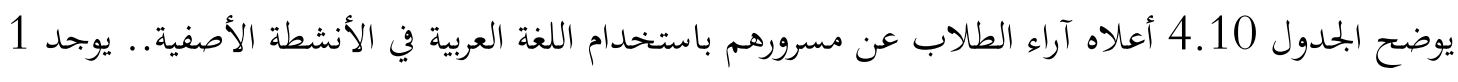
طالب أو ما يعادل 2.5\% من يجيب غير موافق تام عن مسرورهم باستخدام اللغة العربية في الأنشطة الأصفية. ثم الطلاب الذين أجابوا غير موافق على أغم مسرور باستخدام اللغة العربية في الأنشطة الأصفية21 طالبا أو ما يعادل 52.5\%. ثم الطلاب الذين أجابوا موافق على أفم مسرور باستخدام اللغة العربية في الأنشطة الأصفية 14 طلاب أو ما يعادل 24.5\%، والطلاب الذين أجابوا موافق تام على أفم مسرور باستخدام اللغة العربية في الأنشطة الأصفية 4 طلاب أو ما يعادل 10\%.

2.

أ. أعترف أن اللغة العربية مفيدة في التحدث (جدوال 4.11) 
يوضح الجدول 4.11 أعلاه آراء الطلاب عن الإعتراف أن اللغة العربية مفيدة في التحدث. لا يوجد الطالب أو ما يعادل 0\% ممن يجيبون غير موافق تام عن الإعتراف أن اللغة العربية مفيدة في التحدث. ثم الطلاب الذين أجابوا غير موافق على الإعتراف أن اللغة العربية مفيدة في التحدث 1 طالب أو ما يعادل 2.5\%. ثم الطلاب الذين أجابوا موافق على الإعتراف أن اللغة العربية مفيدة في التحدث 8 طلاب أو ما يعادل20\%، والطلاب الذين أجابوا موافق تام على الإعتراف أن اللغة العربية مفيدة في التحدث 31 طالبا أو ما يعادل 77.5\%.

ب. أشعر أن اللغة العربية هي تاج المعهد التي يجب الحفاظ عليها (جدوال 4.12) يوضح الجدول 4.12 أعلاه آراء الطلاب عن شعورهم أن اللغة العربية هي تاج المعهد التي يجب الحفاظ عليها. لا يوجد الطالب أو ما يعادل 0\% ممن يجيبون غير موافق تام أن اللغة العربية هي تاج المعهد التي يجب الحفاظ عليها. ثم الطلاب الذين أجابوا غير موافق على أن اللغة العربية هي تاج المعهد التي يجب الحفاظ عليها 2 طالبان أو ما يعادل 5\%. ثم الطلاب الذين أجابوا موافق على أن اللغة العربية هي تاج المعهد التي يجب الحفاظ عليها 4 طلاب أو ما يعادل10\%، والطلاب الذين أجابوا موافق تام على أن اللغة العربية هي تاج المعهد التي يجب الحفاظ عليها 34 طالبا أو ما يعادل 85\%.

\section{ج. أستخدم اللغة العربية كلغة رئيسية في حياتي اليومية (جدوال 4.13)}

يوضح الجدول 4.13 أعلاه آراء الطلاب عن أستخدم اللغة العربية كلغة رئيسية في حياتم اليومية. لا يوجد الطالب أو ما يعادل 0\% من يجيبون غير موافق تام عن إستخدام اللغة العربية كلغة رئيسية في حياتم اليومية. ثم الطلاب الذين أجابوا غير موافق عن إستخدم اللغة العربية كلغة رئيسية في حياتم اليومية 6 طلاب أو ما يعادل 15\%. ثم الطلاب الذين أجابوا موافق عن إستخدم اللغة العربية كلغة رئيسية في حياقم اليومية 14 طلاب أو ما يعادل35\%، والطلاب الذين أجابوا موافق تام عن إستخدم اللغة العربية كلغة رئيسية في حياتم اليومية 20 طلاب أو ما يعادل 50\%.

د. أنا أكثر مؤدباً إذا كنت أتكلم باللغة العربية في بيئة المعهد (جدوال 4.14) 
يوضح الجدول 4.14 أعلاه آراء الطلاب على أفم أكثر مؤدباً إذا كانوا يتكلمون باللغة العربية في بيئة المعهد. لا يوجد الطالب أو ما يعادل 0\% من يجيبون غير موافق تام على أكثر مؤدباً إذا كانوا يتكلمون باللغة العربية في

بيئة المعهد. ثم الطلاب الذين أجابوا غير موافق على أفم أكثر مؤدباً إذا كانوا يتكلمون باللغة العربية في بيئة المعهد 9 طلاب أو ما يعادل 22.5\%. ثم الطلاب الذين أجابوا موافق على أفم أكثر مؤدباً إذا كانوا يتكلمون باللغة العربية في بيئة المعهد 15 طلاب أو ما يعادل37.5\%، والطلاب الذين أجابوا موافق تام على بـ أفم أكثر مؤدباً إذا كانوا يتكلمون باللغة العربية في بيئة المعهد 16 طلاب أو ما يعادل 40\%.

\section{3 - 3 الوعي بالمعايير اللغوية}

أ. أستخدم اللغة العربية القياسية عندما أدرس في الفصل (جدوال 4.15)

يوضح الجحدول 4.15 أعلاه آراء الطلاب عن إستخدم اللغة العربية القياسية عندما الدراسة في الفصل. لا يوجد الطالب أو ما يعادل 0\% من يجيبون غير موافق تام عن إستخدم اللغة العربية القياسية عندما الدراسة في الفصل. ثم الطلاب الذين أجابوا غير موافق عن إستخدم اللغة العربية القياسية عندما الدراسة في الفصل 11 طلاب أو ما يعادل 57.5\%. ثم الطلاب الذين أجابوا موافق عن إستخدم اللغة العربية القياسية عندما الدراسة في الفصل 6 طلاب أو ما يعادل15\%، والطلاب الذين أجابوا موافق تام عن إستخدم اللغة العربية القياسية عندما الدراسة في الفصل 23 طالبا أو ما يعادل 57.5\%.

ب. أستخدم اللغة العربية القياسية عندما أتكلم مع الأستاذ (جدوال 4.16) يوضح الجدول 4.16 أعلاه آراء الطلاب عن إستخدم اللغة العربية القياسية عندما التكلم مع الأستاذ. لا يوجد الطالب أو ما يعادل 0\% ممن يجيبون غير موافق تام عن إستخدم اللغة العربية القياسية عندما التكلم مع الأستاذ. ثم الطلاب الذين أجابوا غير موافق عن إستخدم اللغة العربية القياسية عندما التكلم مع الأستاذ 18 طلاب أو ما يعادل 45\%. ثم الطلاب الذين أجابوا موافق عن إستخدم اللغة العربية القياسية عندما التكلم مع الأستاذ 12 طلاب أو ما يعادل37.5\%، والطلاب الذين أجابوا موافق تام عن إستخدم اللغة العببية القياسية

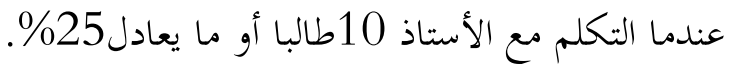


ج. أستخدم اللغة العربية القياسية عندما أتكلم مع أصدقاء خارج الفصل (جدوال 4.17) يوضح الجدول 4.17 أعلاه آراء الطلاب عن أستخدم اللغة العربية القياسية عندما التكلم مع الأصدقاء خارج الفصل. لا يوجد الطالب أو ما يعادل 0\% ممن يجيبون غير موافق تام عن أستخدم اللغة العربية القياسية عندما التكلم مع الأصدقاء خارج الفصل. ثم الطلاب الذين أجابوا غير موافق عن إستخدم اللغة العربية القياسية عندما التكلم مع الأستاذ 21 طلاب أو ما يعادل 52.5\%. ثم الطلاب الذين أجابوا موافق عن أستخدم اللغة العربية القياسية عندما التكلم مع الأصدقاء خارج الفصل 9 طلاب أو ما يعادل22.5\%، والطلاب الذين أجابوا موافق تام عن أستخدم اللغة العربية القياسية عندما التكلم مع الأصدقاء خارج الفصل 10 طالبا أو ما يعادل25\%.

د. أستخدم اللغة العربية القياسية في الأنشطة الأصفية (جدوال 4.18)

يوضح الجدول 4.18 أعلاه آراء الطلاب عن إستخدم اللغة العربية القياسية في الأنشطة الأصفية. لا يوجد الطالب أو ما يعادل 0\% ممن يجيبون غير موافق تام عن عن إستخدم اللغة العربية القياسية في الأنشطة الأصفية. ثم الطلاب الذين أجابوا غير موافق عن عن إستخدم اللغة العربية القياسية في الأنشطة الأصفية 28 طالبا أو ما يعادل 70\%. ثم الطلاب الذين أجابوا موافق عن إستخدم اللغة العربية القياسية في الأنشطة الأصفية 8 طلاب أو ما يعادل20\%، والطلاب الذين أجابوا موافق تام عن إستخدم اللغة العربية القياسية في الأنشطة الأصفية 4

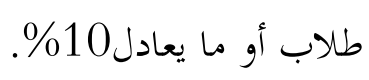

الفصل الثالث: قدرة الطلاب على التحدث باللغة العربية بمعهد الشيخ حسن اليماني.

$$
\text { 1 - 1 إستخدام اللغة العربية في الفصل }
$$

اللغة العربية هي لغة التى يستعمل الطلاب في الفصول الدراسية لتعلم اللغة العربية والدين التي توزع في مواضيع النحو، وتمرين اللغة، ودين الإسلام، والتوحيد،و المخفوظات، والمطالعة. مقدمة للغة العربية لازمة في تعلم هذه المواضيع. إن إستخدام اللغة العربية في تعلم اللغة العربية والدين وهو أمر لا بد منه لجميع المعلمين وأيضا لمجميع الطلاب الذين يدرسون. 
جعل اللغة العربية مقدمة للتفاعلات التعليمية تعني أن لدى الطلاب أساسًا قويًا لتعلم الدين، نظرًا إلى أساس الشريعة الإسلامية المكتوبة بالعربية. بالإضافة إلى ذلك، يتم كتابة جميع الموضوعات العربية والدينية باللغة العربية. يستند الإلتزام باستخدام اللغة العربية في الفصل لموضوعات محددة مسبقًا على المنهج الذي ينطبق تحديدًا على معهد الشيخ حسن اليماني. 18

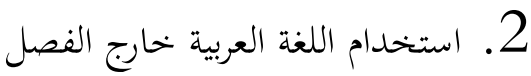

على أساس الملاحظة أن في خارج الفصل، جميع الطلاب ملزمون بشكل خاص باستخدام اللغة العربية كلغة للتعليم في الثفاعل في جميع المواقف والأماكن. مطلوب استخدام اللغة العربية أو وفقًا للإعدادات عند التفاعل مع جميع الأجزاء أو الأقسام في معهد الشيخ حسن اليماني. ولكن في الأنشطة اللأصفية الطلاب

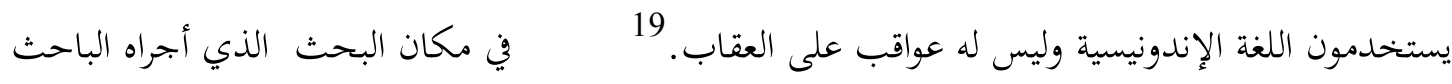
في معهد الشيخ حسن اليماني ، أعطى الباحث تقييمات حول القدرة على التحدث باللغة العربية. التقييمات هي كما يلي:

1. حفظ المفردات: يقوم الباحث بتقييم مستوى قدرة الطلاب في الحفظ كل مفردات في نصوص المحادثة العربيةالتي تم منحها من قبل المعلم وتقييم القدرة على حفظ المفردات الطلاب عندما تعطى اختبارًا من قبل الباحث خارج ساعات الدرس. 2. مخرج الحروف: يقوم الباحث بتقييم دقة الطلاب في نطق كل حرف الواردة في المفردات العربية. 3. القواعد اللغة: يقوم الباحث بتقييم حقيقة اللغة العبية في العمل التواصل / الاتصالات العربية. ويككن إعطاء مستوى محدد مسبقًا من التقييم الباحث، وهي:

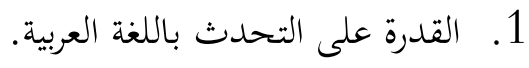
2. - أقل قدرة على التحدث باللغة العربية 


$$
\text { 3. ت غير قادر على التحدث باللغة العربية. }
$$

مستوى مهارات التحدث باللغة العربية لدى طلاب معهد الشيخ حسن اليماني التي يمكن وصفها في

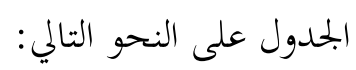

قدرة الطلاب على التحدث باللغة العربية

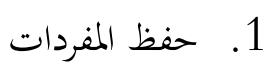

القدرة على حفظ المفردات في التحدث باللغة العربية هناك:

أ. 22 طالبا أو 55\% قادرين على حفظ المفردات العربية

ب. 14 طلاب أو 35\% أقل قدرة على حفظ المفردات العربية

ج. 4 طلاب أو 10\% غير قادرين على حفظ المفردات العربية

2. مخرج الحروف

القدرة على التحدث باللغة العربية مع النطق هناك حق:

أ. 12 طلابا أو 30 \% قادرين على نطق الحروف بشكل صحيح

ب. 20 طلاب أو 50\% أقل قادرين على نطق الحروف بشكل صحيح

ج. 8 طلاب أو 20\% غير قادين على نطق الحروف بشكل صحيح

3. - 5 - (اعواعد اللغة العربية

القدرة على استخدام القواعد الصحيحة في التحدث اللغة العربية، وهي على النحو التالي:

أ. 18 طلاب أو 45\% قادرين على استخدام القواعد الصحيحة في التحدث اللغة العربية

ب. 16 طلاب 40\% أقل قدرة على استخدام القواعد الصحيحة التحدث باللغة العربية

ج. 6 طلاب أو 15\% غير قادرين على استخدام القواعد الصحيح في التواصل باللغة العربية 


\section{الفصل الرابع تأثير موقف اللغة لطلاب معهد الثيخ حسن اليمانى على قدرة التحدث باللغة العربية}

ستجيب نتائج هذ البحث على صيغة المشكلات المطروحات في هذه الرسالة يعني لمعرفة تأثير موقف اللغة لطلاب معهد الشيخ حسن اليمانف على قدرة التحدث باللغة العربية العام 2018.لإسترداد البيانات من المتغيرتين، يستخدم الباحث الإستبينات و الوثائق. تراكمت البيانات ثم تحليلها بإستخدام التحليل الإحصاء و التحليل الوصفي، لمعرفة وصف المتغيرتين. تواجد نتائج البحث يمكن وصفها على النحو التالي:

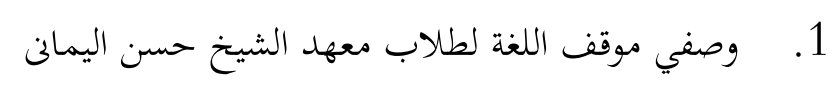

جمع الباحث البيانات من خلال إستبيانات عن موقف اللغة لطلاب معهد الشيخ حسن اليمان.

من خلال جمع درجة الإجابة على بعض التصريح في شكل إستبيان مقدم لطلاب معهد الشيخ حسن اليمانى، فالحصول على أعلى قيمة 47 والحصول على أدنى قيمة 40 مع عينة إجمالية من 40 طالبا. لإنشاء جدول توزيع تردد، تكون الخطوات التي سيتم إتخاذهاكما يلي:

$$
\text { صف= قيمة عالية - انفخاض قيمة }
$$

$$
\begin{gathered}
40-47= \\
7= \\
\text { ب. عدد الصف الفاصل }=
\end{gathered}
$$

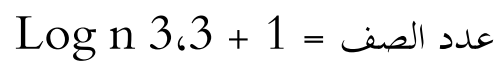

$$
40 \log 3,3+1=
$$

$$
1,6 \cdot 3,3+1=
$$$$
5,28+1=
$$

6 6دور 6 =

ج. عدد الفصل حساب طول الصف الفاصل 
طول الصف الفاصل =

$=\frac{8}{6}$

2 3 1 =

$$
\begin{aligned}
& \text { د. حساب الإجمالي } \\
& =\quad \text { إجمالي } \bar{x} \frac{\sum f_{i} x_{i}}{\sum f_{i}} \\
& =\frac{1786}{40} \\
& 44 ، 65= \\
& \text { ذ. حساب sd } \\
& \sqrt{\frac{45, \mathbf{8 4}}{4 \theta-1}} \sqrt{\frac{\sum f i(x i-x)^{2}}{n-1}} \mathbf{S}_{\mathbf{D}}= \\
& = \\
& \sqrt{11,5856}=
\end{aligned}
$$$$
3 ، 40=
$$

أجرى نتائج التحليل في معهد الشيخ حسن اليمانى، وسع البحث جمع البيانات من خلال إستبيانات عن موقف اللغة لطلاب معهد الشيخ حسن اليمانف فيها التصريح الإجابية و التصريح السلبية، ويكن رؤيتها إلى جدول التالي:

توزيع وتيرة و نسبة نتئج موقف اللغة لطلاب معهد الشيخ حسن اليمانى، فالحصول على أعلى قيمة 47 والحصول على أدنى قيمة 40 العديد من فئة الفصل هي 4 و يكون طول فئة الفصل 2، تواجد قيمة متوسطة

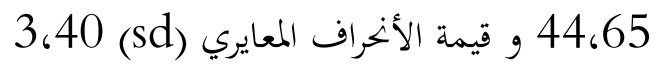


ع. إنشاء جدول لتصنفة الإصابة Interval $=\frac{\text { rentang nilai }}{\text { banyak kelas }}$

$$
=\frac{4740}{2}
$$$$
4=3.5=
$$

فالحصول طول الفصل هو 4 و مسافة الفصل هي 3 وقفا لفئة محددة. موقف اللغة لطلاب في مسافة

40-43 بتردد من 10 و نسبة 25\% دخلت في فئة منخفضة. موقف اللغة لطلاب في مسافة 44-47 بتردد من 30 و نسبة \% 75 دخلت في فئة مرتفع.

ولذالك، يمكن الإستنتاج أن موقف اللغة لطلاب معهد الشيخ حسن اليمانى دخلت في فئة المرتفع بتردد من 30 و نسبة 75 من 2. وصفي قدرة الطلاب علي التحدث باللغة العربية جدوال 4.23 نتائج قدرة الطلاب على التحدث باللغة العربية بناء على جدول 4.23 فالحصول على أعلى قيمة 96 والحصول على أدنى قيمة 73 مع عينة إجمالية من 40 شخصا. لإنشاء جدول توزيع تردد، تكون الخطوات التي سيتم إتخاذهاكما يلي: أ. صف= قيمة عالية - انفخاض قيمة $73-96=$ $23=$ ب. عدد الصف الفاصل

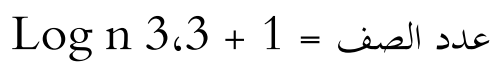
$40 \log 3.3+1=$ 
Shaut Al-'Arabiyah

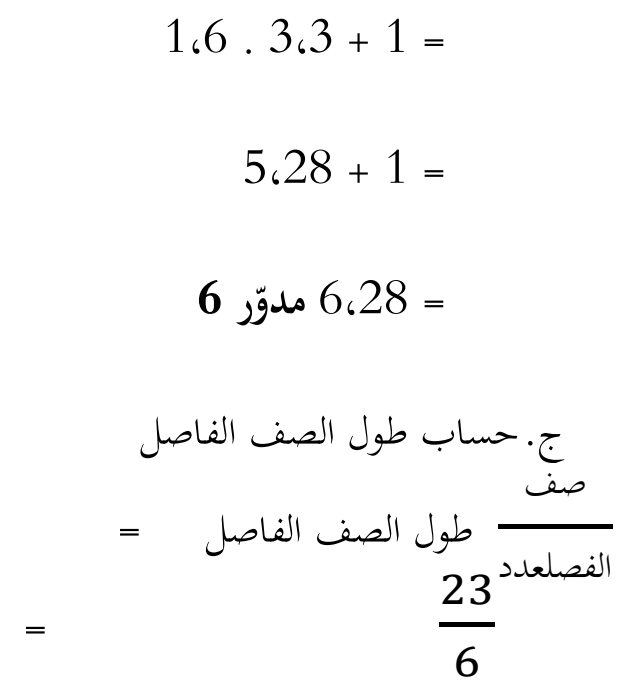

4 8 3 = 3 مدوّر

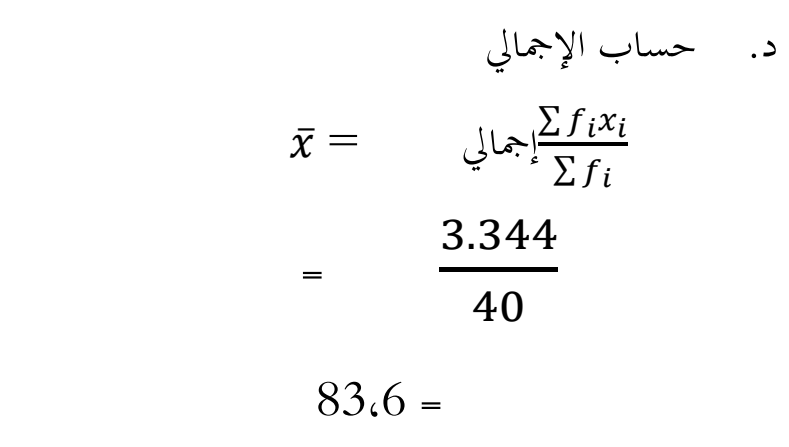

$\sqrt{\frac{\sum f i(x i-x)^{2}}{n-1}} \sqrt{\frac{1.183,6}{4 \theta-1}} \mathbf{S}_{\mathbf{D}}=$
$=$

$\sqrt{30,3487}$

$5,50=$ 
أجرى نتائج التحليل عن قدرة الطلاب على التحدث باللغة العربية، يمكن رؤيتها إلى جدول التالي: توزيع وتيرة و نسبة نتئج قدرة الطلاب على التحدث باللغة العربية، فالحصول على أعلى قيمة 96 والحصول على أدنى قيمة 73 العديد من فئة الفصل هي 6 و يكون طول فئة الفصل 4، تواجد قيمة متوسطة 83،6 م3و قيمة الأنخراف المعايري $5.50(\mathrm{sd})$ ر. إنشاء جدول لتصنفة الإصابة Interval $=\frac{\text { rentang nilai }}{\text { banyak kelas }}$ $=\frac{96-74}{4}$ $6=5,75=$

بناء على جدول 4.25 فالحصول طول الفصل هو 6 ومسافة الفصل هي 4 وقفا لفئة محددة. نتائج قدرة الطلاب على التحدث باللغة العربية في مسافة 73-78 بتردد من 4 و نسبة 10\% دخلت في فئة منخفضة جدا. نتائج قدرة الطلاب على التحدث باللغة العربية في مسافة 79-84 بتردد من 20 و نسبة 50\% دخلت في فئة منخفضة. نتائج قدرة الطلاب على التحدث باللغة العربية في مسافة 85-90 بتردد من 11 و نسبة \% \% 5، 27 دخلت من فئة كافا. نتائج قدرة الطلاب على التحدث باللغة العربية في مسافة 91-96 بتردد من 5 و نسبة \% 12، 12، دخلت من فئة كافا جدا.

ولذالك، يمكن الإستنتاج نتائج قدرة الطلاب على التحدث باللغة العربية دخلت في فئة منحفضة بمسافة 7984 بتردد من 20 و نسبة 50\%.

3. تأثير موقف اللغة لطلاب معهد الشيخ حسن اليمانى على قدرة التحدث باللغة العربية سيتم تحليل البيانة الإحصائية هي قيم الإستبيانات وقيم موقف اللغة لطلاب معهد الشيخ حسن اليمانى، وقيم قدرة الطلاب على التحدث باللغة العربية، وقيم تأثير موقف اللغة لطلاب معهد الشيخ حسن اليمانى على قدرة 
التحدث باللغة العربية. و لذالك سيشرح الحساب أدناه للحصول على معامل موقف اللغة لطلاب معهد الشيخ حسن اليمانى على قدرة التحدث باللغة العربية حتى يمكن التخاذ تفسير البيانة. المساعدة لحساب الإحصاءات

$$
\begin{aligned}
& \text { من نتائج الحساب يكصل قيم عليه: } \\
& \mathbf{X}=1796 \\
& \text { Y }=3346 \\
& \mathbf{X}^{\mathbf{2}}=80913 \\
& Y^{2}=281168 \\
& \mathbf{X Y}=150365 \\
& \text { ثم بعد ذالك يدخل القيم في الصيغة : } \\
& r_{x y}=\frac{\sum x y}{\sqrt{\left\{\sum X^{2}\right\}\left\{\sum Y^{2}\right\}}} \\
& r_{x y}=\frac{150365}{\sqrt{\{80913\}\{281168\}}}
\end{aligned}
$$

$$
r_{x y}=\frac{150365}{\sqrt{2275014} 64}
$$

$$
r_{x y}=\frac{150365}{15083,151}
$$

$$
r_{x y}=0.996
$$


من النتيجة يمكن إستتاج أن هناك تأثيرة إحابية بين موقف اللغة لطلاب معهد الشيخ حسن اليمانى و قدرة الطلاب على التحدث باللغة العربية. يمكن رؤيتها في جدول الإرشد أدناه، قيم rxy 0 ب9 على مستوى العلاقة "جيد جدا"

\section{جدوال 4.27}

المبادئ التوجيهية تدخل معامل العلاقة

\begin{tabular}{|c|c|}
\hline مسافة المعامل & مستوى العلاقة \\
\hline $0,00-0,199$ & ضعيف جدا \\
\hline $0,20-0,399$ & ضعيف \\
\hline $0,40-0,599$ & وسط \\
\hline $0,60-0,799$ & جيد \\
\hline $0,80-1,000$ & جيد جدا \\
\hline
\end{tabular}

لإختبار أهمية من خلال المقارنة بين r tabel و م يحصل النتائج ritung مitung أكبر من

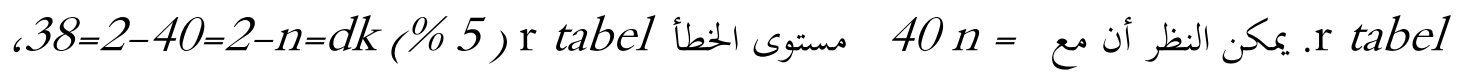

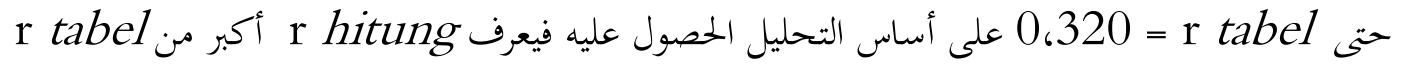

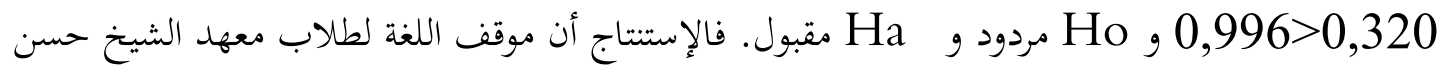
اليمان فيها علاقة إجابية على قدرقم في التحدث باللغة العربية في معهد الشيخ حسن اليمان هذا ينطبق عينة 


$$
\begin{aligned}
& t=\frac{r \sqrt{n-2}}{\sqrt{1-r^{2}}} \\
& t=\frac{0,996 \sqrt{40-2}}{\sqrt{1-0,996^{2}}} \\
& t=\frac{0,996 \sqrt{38}}{\sqrt{1-0,992016}} \\
& t=\frac{0,996.6,164}{\sqrt{0,009975}} \\
& t=\frac{6,139344}{0,0998749218} \\
& t=61,470
\end{aligned}
$$

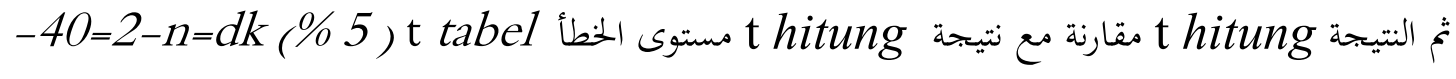

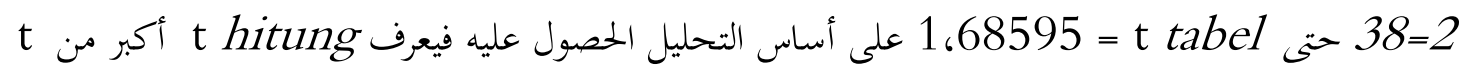
tabel ذكر أن تأثير موقف اللغة لطلاب معهد الشيخ حسن اليمانى على قدرة التحدث باللغة العربية

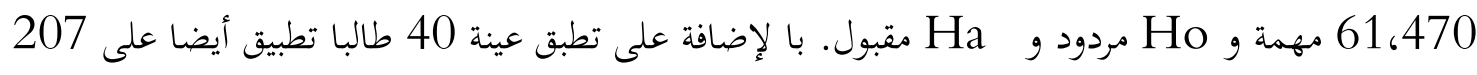
طالبا. فالإستنتاج أن موقف اللغة لطلاب معهد الشيخ حسن اليمانى له تأثيرة إجابية و أهمية على قدرة التحدث باللغة العربية لطلاب معهد الشيخ حسن اليمانى. الخحاتمة - - (المة 
وإعتمادا على مشكلات البحث السابقة وإجاباتما في بحوث بعدها، فيكون الباحث أن يأتي خلاصة البحث كما

1. نتائج موقف اللغة لطلاب معهد الشيخ حسن اليمانف في المسافة 40-43 بتردد من 10 و نسبة 25\% دخلت في فئة منخفضة. وفي المسافة 44-47 بتردد من 30 و نسبة \% 75 دخلت في فئة مرتفع. 2. نتائج قدرة الطلاب علي التحدث باللغة العربية في المسافة 73-78 بتردد من 4 و نسبة 10\% دخلت في فئة منخفضة جدا. وفي المسافة 79-84 بتردد من 20 و نسبة 50\% دخلت في فئة منخفضة. وفي المسافة 85-90 بتردد من 11 و نسبة \% 27،5 دخلت من فئة كافا. وفي المسافة 91-96 بتردد من 5 و نسبة \% 12,5 دخلت في فئة كافا جدا.

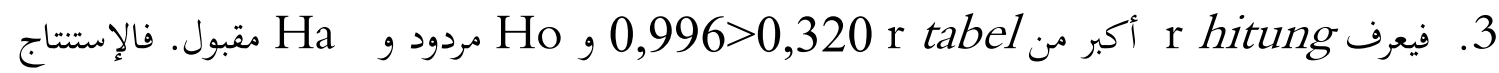
أن موقف اللغة لطلاب معهد الشيخ حسن اليمانى لها تأثير إحابي على قدرقم في التحدث باللغة العربية وهي في مستوى (جيد جدا). لذلك يحتاج الطلاب إلى إتخاذ موقف إيجابي والقيام بوظائفهم بحيث تنمو الإرادة في التطوير والحفاظ على اللغة العربية.

$$
\text { المراجع }
$$

أحمدي، أبو. Psikologi Sosial. - جاكرتا: Rineka Cipta، 2009.

أريكونتوا، سوحرسيمي.Prosedur Penelitian. جاكرتا:2002 PT. Rineka Cipta. أزوار، سيف الدين. Pikap Manusia Teori dan Pengukurannya. جغحاكرتا: Pustaka Belajar، 2016. إيزان، أحمد. Metode pembelajaran Bahasa Arab. باندونغ: Humaniora، 2009. ديندي، وسوغونو. Mahir Berbahasa Indonesia Dengan Benar. جاكرتا: Gramedia Pustaka Utama، .2009 الخيز، عبدويوين آجوستينا. Sosiolinguistik Perkenalan Awal. جاكرتا: 2010،PT. Rineka Cipta. 
Sosiolinguistik Suatu Pendekatan Pembelajaran Bahasa dalam Masyarakat الرحمان، فتح Multikultural سكماديناتا، نا شوضح. Metode Penelitian Pendidikan. باندونغ: PT. Remaja Rosdakarya، 2015. سوديونو، أنس. Pengantar Statistik Pendidikan. جاكرنا: Rajawali Press، 2009. سوجدانا.Metode Statistik. بندونغ: ترسيتو، 1996. سو اندى،نينغاه. Sosiolinguistik.جغاكرتا: Graha Ilmu، سو غيونو. Metode Peneltian Administrasi ، باندونج: Alfabeta، 2010. سو غييونو. Metode Penelitian Kuantitatif, Kualitatif dan R \& بندونغ: Alfabeta، 2012. سوكاردى. أساليب ومناهج البحث في الكفاءة التعليمية. جاكرتا: PT Bumi Aksara، 2010. السلامهنور. Statistika Penelitian. مكاسر: طبعة: 1، علاء الدين ينفرستى فريس،2011. ضيف، شوقى. الدعجم الوسيط. مصرى: مكتبة صورق الدولية، 2011. غونتور، هنري تريغان. Berbicara Sebagai Suatu Keterampian Berbahasa. باندونغ: Angkasa

$$
\text { الغنى، عبد. معجم الغني. بيروت: دار الكتب العلمية، } 2008 \text { ، } 2013 .
$$

فو آد، أحمد أفندى. Metode Pengajaran Bahasa Arab. مالانغ: Misykat، 2005. فتنيدا،منصور. Sosiolinguistik. باندونغ: Angkasa، 2013.

فورقان، عريف.Pengantar Penelitian dalam Pendidikan. جاكرتا: Pustaka Belajar. 2004. محيمن، أحمد ازيت. Urgensi Pendidikan Karakter di Indonesia. جغاكرتا: Ar-Ruz Media، 2011. مستقي. Membina Kemampuan Berbahasa Panduan ke Arah Kemahiran Berbahasa . جاكرتا: PT .1994 ،Gramedia Utama 
نينا، وشام. Psikologi Sosial Sebagai Akar Ilmu Komunikasi. باندونغ: Simbiosa Rekatama Media،

ورسون، أحمد منور .قاموس الهنور (عربـ اندونبيسي). سور ابايا، 1984Progresif Pustaka. وسيطو، حرماو ان. Pengantar Metodologi Penelitian. جاكرنا: Utama Gramedia Pustaka، 1998. درماوان، آجيف. Metode Pembelajaran Bahasa Arab. باندونغ: PT. Remaja Rosdakarya، 2009. يوسف، تاياس. Metode Pengajaran Bahasa Arab. مالانغ: Misykat، 2005. 